Technical Report Documentation Page

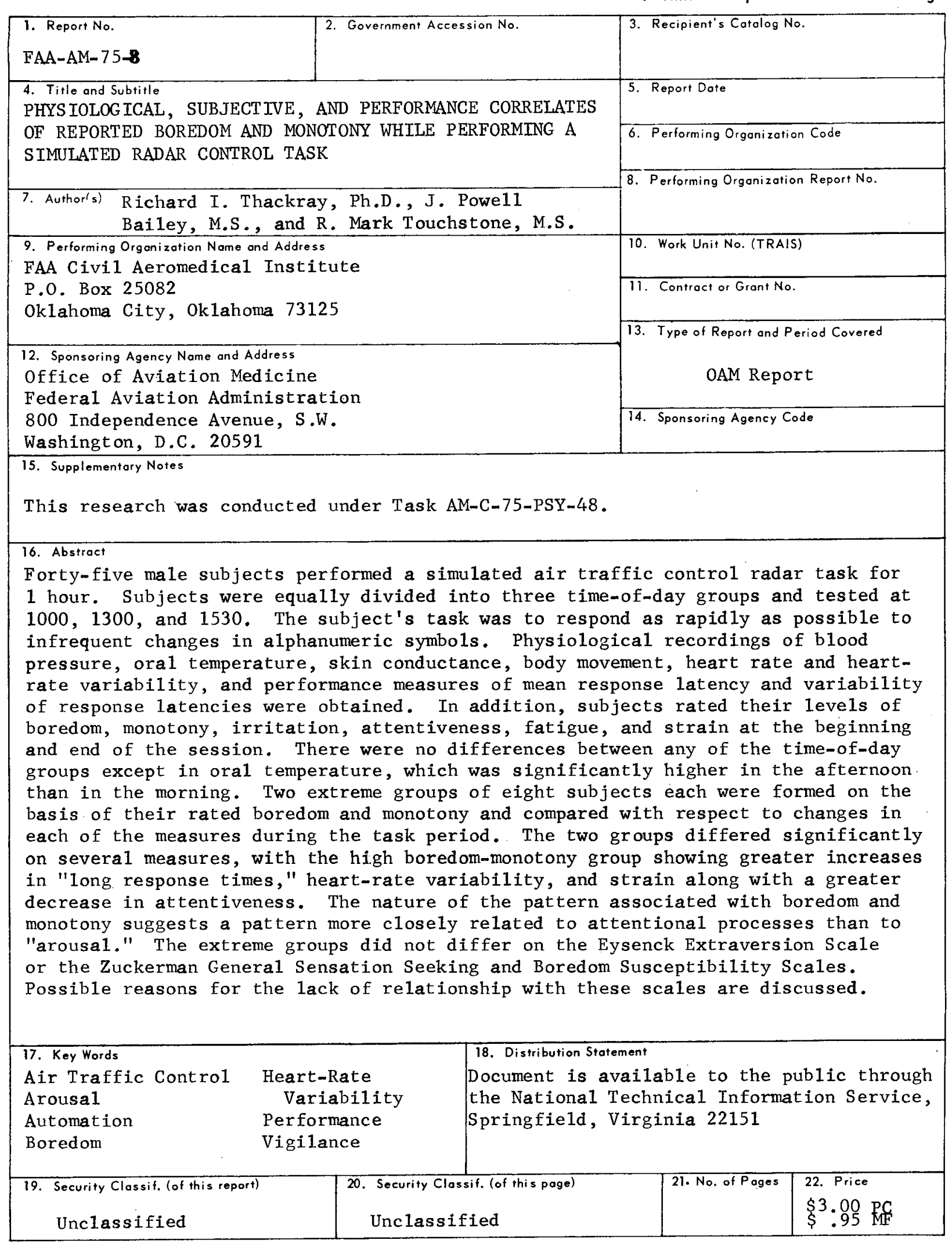

Form DOT F 1700.7 (8-72) Reproduction of completed page authorized 


\section{PHYSIOLOGICAL, SUBJECTIVE, AND PERFORMANCE CORRELATES OF REPORTED BOREDOM AND MONOTONY WHILE PERFORMING A SIMULATED RADAR CONTROL TASK}

\section{Introduction.}

There is an increasing trend toward automation of air traffic control systems. While present systems can best be described as semiautomated and still leave the controller with a considerable amount to do, projected trends in the development of fully automated systems suggest the distinct possibility that the future role of the controller may be far more that of a system monitor than that of an active participant in traffic control. Indeed, Barnes and Dickson ${ }^{7}$ have stated that in the future, the controller may well "manage by exception in that his direct involvement would only be required when certain system limits were exceeded or in case of malfunction (p. 26)."

Fully automated air traffic control systems may be technologically feasible and even advantageous from a cost-effectiveness standpoint. However, it seems likely that present-day controllers would find the job of passively monitoring a virtually autonomous system to be monotonous, boring, and unsatisfying. Because of this, certain tradeoffs will ultimately be necessary to achieve man-machine configurations that will minimize the undesirable aspects and maximize efficiency. But, in attempting to make intelligent decisions regarding tradeoffs, we need considerably more information to determine the degree to which, and the manner in which, feelings of boredom and monotony influence performance efficiency in complex vigilance tasks.

There has been virtually no laboratory research relating boredom and monotony to performance since the classic work of Barmack in $1937.6^{6}$ Barmack found that in the performance of a pursuit rotor task as well as in the performance of a repetitive addition task, those individuals who experienced the greatest increase in boredom generally showed increased errors and decreased work output. Boredom was also associated with increased fatioue and irritation along with decreases in attentiveness, oxygen consumption, blood pressure, and, to a lesser extent, heart rate. While this overall pattern of subjective, physiological, and performance changes tended to be associated with boredom in many subjects $(S)$, there were fairly numerous exceptions, and Barmack did little to quantify the degree of interrelationship between these changes.

The present study is essentially an extension of Barmack's early work with the addition of a complex visual monitoring task patterned after contemporary air traffic control radar displays. The primary purpose was to examine in detail the physiological, subjective, and performance changes accompanying reported boredom and monotony during performance of this task.

In a pilot study conducted to investigate various characteristics of the monitoring task, two separate groups of eight $S$ s with no prior experience on the task were tested during a late morning and an early afternoon session. Comparisons of the two sessions suggested greater performance decrement and greater perceived boredom and monotony among $S_{\mathrm{S}}$ in the afternoon group than among those in the morning group. Since several studies (Blake ${ }^{10}$; Colquhoun ${ }^{14}$ ) have reported a slight "post-lunch dip" in performance on some kinds of tasks, it seemed possible that the suggestion of greater decrement among the afternoon group might have been a reflection of this phenomenon. Alternatively, the differences between the two groups could have resulted from a sampling bias, in which the afternoon group was more susceptible to boredom than the morning group.

The existence of a time-of-day effect could seriously confound interpretation of the differences between individuals with respect to rela- 
tionships between boredom-monotony and performance. Consequently, $s$ s in the present study were tested during moming and afternoon sessions in an attempt to determine whether a timeof-day effect had to be considered in interpreting the obtained results.

\section{Method.}

A. Subjects. Forty-fire paid male college students were randonly assigned to three groups of equal size. The groups differed only in the time of day tested: 1000,1300 , or 1530 . All $S$ s were right handed and had no prior experience with the task used.

B. Apparatus and Task Design. A Graflex Model 750 film-strip projector was used to project stimuli onto the rear of a 40-centimeter (diameter) Polacoat screen. The screen itself was located in a console designed to resemble an air traffic control radar unit. The stimuli displayed consisted of targets, or "blips," representing aircraft flying along specific routes at various speeds. Adjacent to each target was an alphanumeric symbol consisting of two letters, three numbers, and a final letter. The first two letters identified the aircraft and the three numbers indicated its altitude. For example, SA150 might represent Standard Airlines flying at 15,000 feet. The final letter-."C" or " $\mathrm{N}$ "-indicated the altitude" status of the aircraft; "C" signified that the aircraft was maintaining its assigned altitude, while " $N$ " indicated that the aircraft had departed from its assigned altitude. The occurrence of " $\mathrm{N}$ " constituted a critical event, and the $S$ was instructed to press a button on the right panel of the console whenever he detected that such an event had occurred. There were 10 critical stimuli ("N") in the two successive 30-minute periods of the task. No more than one critical stimulus was ever present on any given frame of the filmstrip, and each critical stimulus reverted to "C" on the next frame. The mean interval between critical stimuli was 3 minutes.

The $S$ was exposed to each filmstrip frame for 15 seconds. With each successive frame of the filmstrip, the targets advanced at simulated airspeeds of either 300 or 600 knots. These two speeds were equally distributed among the targets displayed. The number of targets on any given frame ranged from 6 to 10 with a mean of
8. Targets were distributed across all quadrants of the screen to kecp scanning requirements ap proximately constant. Film advance was automatically controlled by timers, and a shutter mechanism blanked out the screen between frames. The total task was similar to one employed by Adams, Stenson, and Humes. ${ }^{1}$ Figure 1 shows a typical stimulus pattern as displayed to the $S$.

Response times to the critical stimuli were measured in hundredths of a second by means of a Welford Mark $Y$ Serial Event Timer and Recorder (SETAR) with a paper tape output. On each frame of the filmstrip containing a critical stimulus was a small transparent circle near one of the outer edges that allowed light from the projector to fall on a photocell. The output of the photocell activated one of the inputs to the SETiR, which measured elapsed time from frame exposure (stimulus onset) until $S$ 's response. If the elapsed time exceeded 14 seconds, the erent was recorded as an error of omission.

A Beckman Type $R$ Dynograph was used in recording skin conductance, heart rate, body movement, and blood pressure. Heart rate was obtained from Beckman biopotential electrodes attached to the lateral walls of the $S$ 's chest; leads from the electrodes were connected to a cardiotachometer coupler. Biopotential electrodes filled with a saline paste ${ }^{24}$ were attached to the volar surfaces of the index and middle fingers of the $S$ 's left hand. Leads from these electrodes led to a Beckman Type 9844 coupler that measured conductance directly. An arm cuff was used in conjunction with an E\&M Instrument Company electrosphygmograph to obtain recordings of blood pressure. Gross body movement was obtained from a crystal fingerpulse transducer attached to a cushion on the $S$ 's chair. The output of this transducer was amplified and then integrated (by using a pulse integrator), and the pulses were recorded on the Dynograph. Outputs from the cardiotachometer and the pulse integrator also led to the SETAR for subsequent computer analysis of heart rate, heart-rate variability, and frequency of body movement. In addition, one channel of the Dynograph recorded the output of a photocell recessed in the shelf of the $S$ 's console. The purpose of the photocell was to enable the experimenter to visually insure that the $S$ 's right 


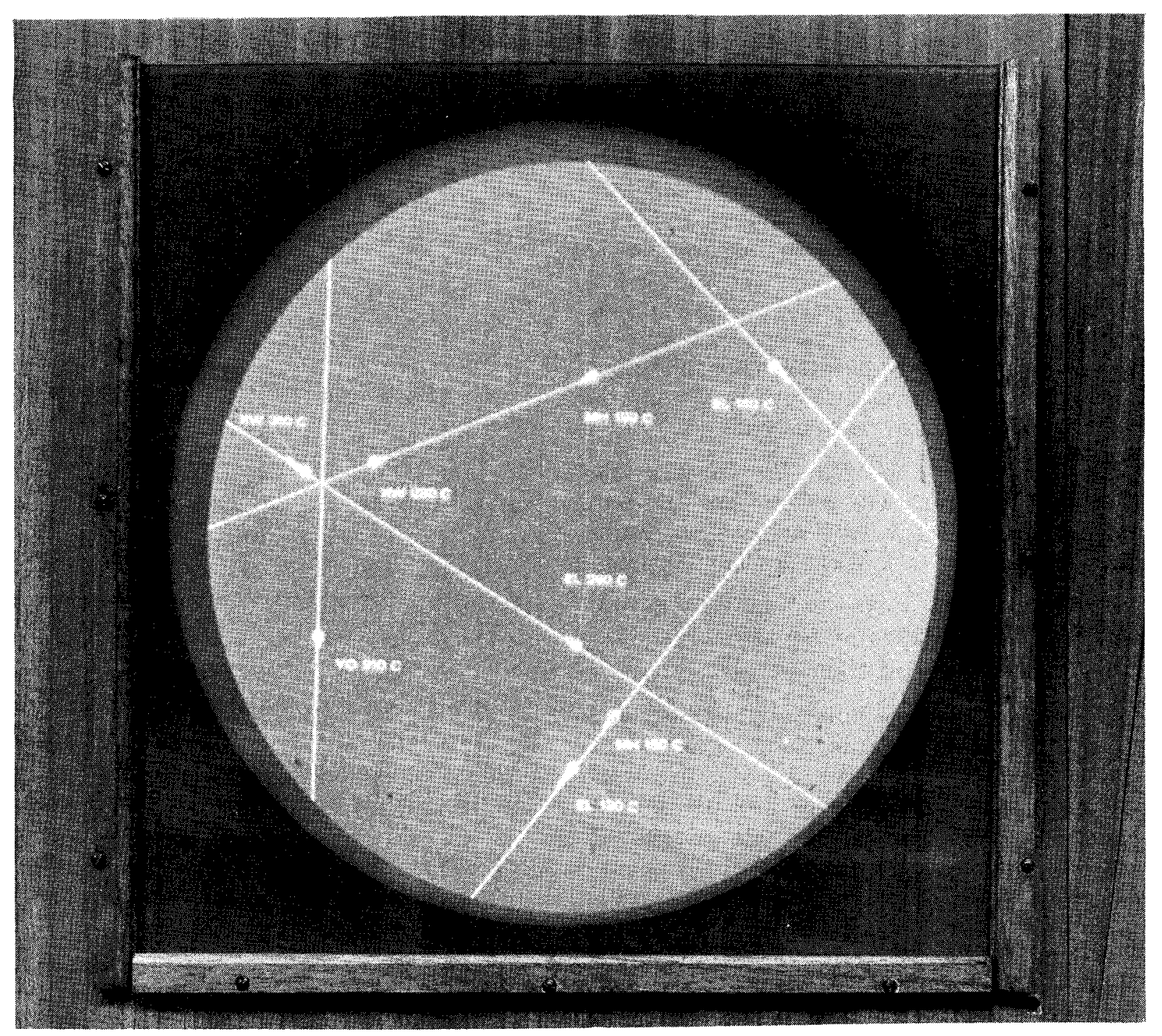

Figure 1. A typical stimulus pattern as displayed to the subject.

hand was located in the position specified at all times. A final physiological measure (oral temperature) was obtained from a standard clinical thermometer. All recording and programing apparatus were located in a separate room from which the $S$ was visible through a one-way mirror.

C. Procedure. On arrival, the $S$ was taken to the testing room, given orientation instructions, and then instrumented for physiological recording. Following this, the $S$ was administered a subjective rating scale dealing with his present feelings, attitudes, and emotions. The $S$ was asked to rate, on a nine-point scale, his levels of attentiveness, fatigue, strain, boredom, and irritation. The items on the rating scale closely approximated those used by Barmack. ${ }^{6}$

The task instructions were then given to the $S$. It was emphasized that the $S$ was to attend to the simulated radar display at all times and to respond as rapidly as possible to any critical stimulus as soon as one was detected. Following completion of the task instructions, three blood pressure recordings were obtained and oral temperature was measured. Precautions were taken to insure that the $S$ did not eat, consume any liquids, or smoke for 30 minutes prior to the time his temperature was measured. 
After the 1-hour task period, blood pressure and oral temperature were again taken, and the $S$ completed a second form of the subjective rating scale. This form was like the first, except that the $S$ was asked to rate each of the items with respect to how he felt near the end of the task he had just completed and an item was added in which the $S$ rated how monotonous he felt the task to be toward the end of the task period. After the $S$ completed the rating scale, the electrodes and blood pressure cuff were removed, and the $S$ was asked to complete Form A of the Eysenck Personality Inventory ${ }^{20}$ and the Zuckerman Sensation Seeking Scale. ${ }^{30}$

D. Measurement of the Performance and Physiological Data. The performance data were computer processed and the following measures were obtained for each of the 30 -minute periods:

- Mean response latency to the critical stimuli.

- Standard deviation of response latencies.

- Number of critical stimuli missed.

The computer program described in a previous report ${ }^{28}$ was used to obtain the mean and standard deviation of heart rate for each successive 5 -minute period. These were then averaged to give values for the two 30 -minute periods. A separate computer program summed the number of pulses from the body movement integrator for each 30-minute period. Conductance was measured during the first, middle, and last 5 minutes of the task period and averages were computed for the first and second half hours. In measuring the three blood pressure recordings taken at the beginning and end of the task period, the systolic pressure was determined by the appearance of the first Korotkoff sound as recorded on the Dynograph. Diastolic pressure was taken to be the first Korotkoff sound having an amplitude less than one-third the amplitude of the maximum recorded sound. This technique has been used by Cartwright ${ }^{12}$ and correlates well with conventional clinical measurements. The three systolic and diastolic measures were averaged separately for the beginning and end of the task. Oral temperature was read to the nearest tenth of a degree.

\section{Results.}

A. Time-of-Day Effects. Performance data for the three time-of-day groups are shown in
Table 1. Analyses of variance revealed no significant $(p>.05)$ group, measurement period, or interaction effects for either mean latency or variability of response latencies to the critical task stimuli. Since none of the critical stimuli was missed by any of the $S \mathrm{~s}$, this measure is not included in the table.

TABLE 1. Mean Values obtained for Each Performance

Variable for the Three Time-of-Day Groups ${ }^{2}$

\begin{tabular}{lllc}
\hline & & \multicolumn{2}{c}{30 -Minute Periods } \\
\cline { 3 - 4 } Variable & Croup & 1 & 2 \\
\hline & 1000 & 2.82 & 2.73 \\
Latency to & 1300 & 2.65 & 2.76 \\
Critica1 St imu1i (sec) & 1530 & 3.02 & 2.86 \\
& 1000 & 0.78 & 0.97 \\
SD of Latencies to & 1300 & 0.84 & 0.93 \\
Critical Scimuli (sec) & 1530 & 0.76 & 0.91 \\
\hline
\end{tabular}

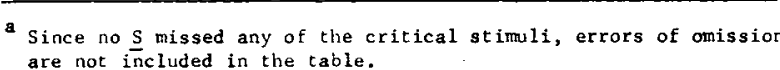

Table 2 gives the physiological values obtained for the three groups. Analyses of variance yielded significant $\mathbf{F}$ values $(p<.01)$ for periods for all variables except heart-rate variability.

TABLE 2. Mean Values obtained for Each Physiological

variable for the Three Time-of-Day Groups

\begin{tabular}{|c|c|c|c|}
\hline \multirow[b]{2}{*}{ Variable } & \multirow[b]{2}{*}{ Group } & \multicolumn{2}{|c|}{ Measurement Period } \\
\hline & & 1 & 2 \\
\hline $\begin{array}{l}\text { Conductance } \\
(\mu \text { mhos })^{2}\end{array}$ & $\begin{array}{l}1000 \\
1300 \\
1530\end{array}$ & $\begin{array}{r}9.35 \\
12.30 \\
11.82\end{array}$ & $\begin{array}{r}8.54 \\
11.44 \\
11.02\end{array}$ \\
\hline $\begin{array}{l}\text { Oral Temperatare } \\
\text { (degrees F.) }\end{array}$ & $\begin{array}{l}1000 \\
1300 \\
1530\end{array}$ & $\begin{array}{l}98.22 \\
98.05 \\
98.62\end{array}$ & $\begin{array}{l}97.99 \\
97.87 \\
98.19\end{array}$ \\
\hline $\begin{array}{l}\text { Systolic BP } \\
\text { (man } \mathrm{Hg})^{\mathrm{b}}\end{array}$ & $\begin{array}{l}1000 \\
1300 \\
1530\end{array}$ & $\begin{array}{l}126.66 \\
119.71 \\
117.84\end{array}$ & $\begin{array}{l}117.42 \\
112.75 \\
112.44\end{array}$ \\
\hline $\begin{array}{l}\text { Diastolic BP } \\
(\operatorname{man} \mathrm{Hg})\end{array}$ & $\begin{array}{l}1000 \\
1300 \\
1500\end{array}$ & $\begin{array}{l}75.37 \\
76.00 \\
72.33\end{array}$ & $\begin{array}{l}72.75 \\
68.93 \\
72.71\end{array}$ \\
\hline $\begin{array}{l}\text { Heart Rate } \\
(\text { bpm) }\end{array}$ & $\begin{array}{l}1000 \\
1300 \\
1500\end{array}$ & $\begin{array}{l}83.27 \\
73.87 \\
79.58\end{array}$ & $\begin{array}{l}80.27 \\
72.58 \\
76.43\end{array}$ \\
\hline $\begin{array}{l}\text { Heart Rate SD } \\
(\mathrm{bpm})^{\mathrm{a}^{2}}\end{array}$ & $\begin{array}{l}1000 \\
1300 \\
1500\end{array}$ & $\begin{array}{l}7.19 \\
6.89 \\
7.14\end{array}$ & $\begin{array}{l}7.19 \\
7.25 \\
6.97\end{array}$ \\
\hline $\begin{array}{l}\text { Body Movement } \\
\text { (integrator pulses) }\end{array}$ & $\begin{array}{l}1000 \\
1300 \\
1530\end{array}$ & $\begin{array}{l}165.00 \\
118.13 \\
131.40\end{array}$ & $\begin{array}{l}263.60 \\
223.00 \\
205.87\end{array}$ \\
\hline
\end{tabular}

a values shown are for the first and second half hours of the task

${ }^{b}$ values shown are for the beginning and end of the task period. 
All the variables showing significant changes from the first to the second measurement period declined in value except body movement, which showed an increased level of activity. The only variable that differed significantly $(p<.05)$ as a function of time of day was oral temperature. As shown in Table 2, temperature was higher in the late afternoon than in the morning, with a dip occurring during the early afternoon period. The one significant $(p<.05)$ interaction was the periods-by-time-of-day effect for diastolic blood pressure. Table 2 shows that diastolic blood pressure decreased during the measurement periods for the first two time-of-day groups and increased for the last group. The meaning of this particular pattern is unclear.

The rating scale data are given in Table 3. Analyses of variance applied to each of the

TABLE 3. Mean Values obtained for Each Rating Scale variable for the Three Time-of-Day Groups

\begin{tabular}{|c|c|c|c|}
\hline \multirow[b]{2}{*}{ Variable } & \multirow[b]{2}{*}{ Group } & \multicolumn{2}{|c|}{ Measurement Period } \\
\hline & & Prior to Task & End of Task \\
\hline Bored om ${ }^{2}$ & $\begin{array}{l}1000 \\
1300 \\
1530\end{array}$ & $\begin{array}{l}7.80 \\
77.93 \\
7.93\end{array}$ & $\begin{array}{l}4.33 \\
4.93 \\
5.07\end{array}$ \\
\hline Irritation ${ }^{a}$ & $\begin{array}{l}1000 \\
1300 \\
1530\end{array}$ & $\begin{array}{l}8.67 \\
8.93 \\
9.00\end{array}$ & $\begin{array}{l}7.53 \\
8.40 \\
7.93\end{array}$ \\
\hline Attentiveness ${ }^{a}$ & $\begin{array}{l}1000 \\
1300 \\
1530\end{array}$ & $\begin{array}{l}3.60 \\
3.20 \\
2.67\end{array}$ & $\begin{array}{l}5.00 \\
5.00 \\
5.27\end{array}$ \\
\hline Fatigue $^{b}$ & $\begin{array}{l}1000 \\
1300 \\
1530\end{array}$ & $\begin{array}{l}4.00 \\
4.33 \\
4.47\end{array}$ & $\begin{array}{l}5.87 \\
6.20 \\
6.13\end{array}$ \\
\hline $\operatorname{strain}^{a}$ & $\begin{array}{l}1000 \\
1300 \\
1530\end{array}$ & $\begin{array}{l}5.93 \\
6.07 \\
5.67\end{array}$ & $\begin{array}{l}4.93 \\
4.73 \\
5.80\end{array}$ \\
\hline Monotony ${ }^{a}$ & $\begin{array}{l}1000 \\
1300 \\
1530\end{array}$ & $\begin{array}{l}-\cdots \\
\cdots--\end{array}$ & $\begin{array}{l}3.60 \\
3.07 \\
3.07\end{array}$ \\
\hline
\end{tabular}

a Lower numerical values indicate higher levels of the variable.

${ }^{b}$ Higher numerical values indicate higher levels of the variable.

variables (except monotony) revealed that the changes from the first to the second measurement period were significant in every case. $(p<.05)$. The direction of the changes indicated an increase in boredom, irritation, fatigue, and strain from the beginning to the end of the task along with a decrease in attentiveness. There were no significant differences between the timeof-day groups and no significant interactions. A simple analysis of variance of the monotony data revealed no significant difference $(p>.05)$ between groups.

B. Comparison of High and Low BoredomMonotony Groups. The boredom and monotony scores obtained from the rating scale administered at the completion of the task period were summed together for each $S$. From the resulting distribution, eight $S \mathrm{~s}$ with the highest scores and eight with the lowest were selected to form the High and Low Boredom-Monotony Groups. (These groups will henceforth be referred to as the High and Low Groups.) Both groups had identical mean ratings on the boredom scale prior to the beginning of the task. Mean ratings for boredom and monotony at the completion of the task were 2.0 and 1.2 for the High Group and 7.4 and 6.8 for the Low Group. The statements on these scales corresponding to the above numerical values revealed that the High Group experienced moderate to extreme boredom toward the end of the task period and felt the task itself to be extremely monotonous, while the Low Group experienced greater-than-moderate interest in performing the task and did not perceire it to be monotonous.

While not specifically equated for time of day tested, both the High and Low. Groups were approximately equivalent with respect to this variable. Of the High Group, three $S$ s were tested at 1000 , three at 1300 , and two at 1530 ; of the Low Group, three were tested at 1000 , two at 1300 , and three at 1530 .

Mean physiological, performance, and rating scale values for the High and Low Groups are shown in Tables 4, 5, and 6 respectively. Since the two subgroups were formed from the larger group of $45 S \mathrm{~s}$, one would expect the betweenperiods changes for each variable that were significant in Tables 1,2, and 3 to be significant for the data shown in Tables 4, 5, and 6 as well. Analyses of variance applied to the physiological data given in Table 4 revealed this to be the case for all variables except diastolic blood pressure, which showed a significant decline from the beginning to the end of the task period in the larger group but not in the subgroups. There were no significant between-group or interaction effects for any of the variables with the exception of a significant $(p<.05)$ interaction effect for heart-rate variability. As Table 4 shows, heart-rate variability from the first to the second 
TABLE 4. Mean Values obtained for Ench Physiological

variable for the High and Low Boredom-Monotony Group

\begin{tabular}{|c|c|c|c|}
\hline \multirow[b]{2}{*}{ Variable } & \multirow[b]{2}{*}{ Group } & \multicolumn{2}{|c|}{ Measurement Period } \\
\hline & & 1 & 2 \\
\hline $\begin{array}{l}\text { Conduct ance } \\
(\omega \text { mhos })^{2}\end{array}$ & $\begin{array}{l}\text { Low } \\
\text { High }\end{array}$ & $\begin{array}{r}9.12 \\
12.34\end{array}$ & $\begin{array}{r}8.62 \\
11.66\end{array}$ \\
\hline $\begin{array}{l}\text { Oral Temperature } \\
\text { (degrees F.) }\end{array}$ & $\begin{array}{l}\text { Low } \\
\text { High }\end{array}$ & $\begin{array}{l}98.17 \\
98.30\end{array}$ & $\begin{array}{l}98.02 \\
97.81\end{array}$ \\
\hline $\begin{array}{l}\text { Systoli if } \mathrm{BP} \\
(\mathrm{nm} H \mathrm{Hg})^{\mathrm{B}}\end{array}$ & $\begin{array}{l}\text { Low } \\
\text { High }\end{array}$ & $\begin{array}{l}123.74 \\
122.54\end{array}$ & $\begin{array}{l}117.50 \\
114.00\end{array}$ \\
\hline $\begin{array}{l}\text { Diastolic BP } \\
\left(m m \mathrm{H}_{\mathrm{g}}\right)\end{array}$ & $\begin{array}{l}\text { Low } \\
\text { High }\end{array}$ & $\begin{array}{l}79.83 \\
74.83\end{array}$ & $\begin{array}{l}77.71 \\
71.75\end{array}$ \\
\hline $\begin{array}{l}\text { Heart Rate } \\
(\mapsto p m)^{a^{2}}\end{array}$ & $\begin{array}{l}\text { Low } \\
\text { High }\end{array}$ & $\begin{array}{l}80.78 \\
72.41\end{array}$ & $\begin{array}{l}76.79 \\
71.55\end{array}$ \\
\hline $\begin{array}{l}\text { Heart Rate SD } \\
\left(\mathrm{bpm}^{\mathrm{a}} \mathrm{a}^{\mathrm{a}}\right.\end{array}$ & $\begin{array}{l}\text { Low } \\
\text { High }\end{array}$ & $\begin{array}{l}8.35 \\
7.78\end{array}$ & $\begin{array}{l}7.09 \\
8.62\end{array}$ \\
\hline $\begin{array}{l}\text { Body Movement } \\
\text { (integrat or pulses) }\end{array}$ & $\begin{array}{l}\text { Low } \\
\text { High }\end{array}$ & $\begin{array}{r}92.50 \\
172.20\end{array}$ & $\begin{array}{l}160.50 \\
303.40\end{array}$ \\
\hline
\end{tabular}

a Values shown are for the first and second half hours of the task
period.

half of the task period decreased for the Low Group and increased for the High Group.

With regard to the performance data in Table 5 , a significant $(p<.05)$ difference was found

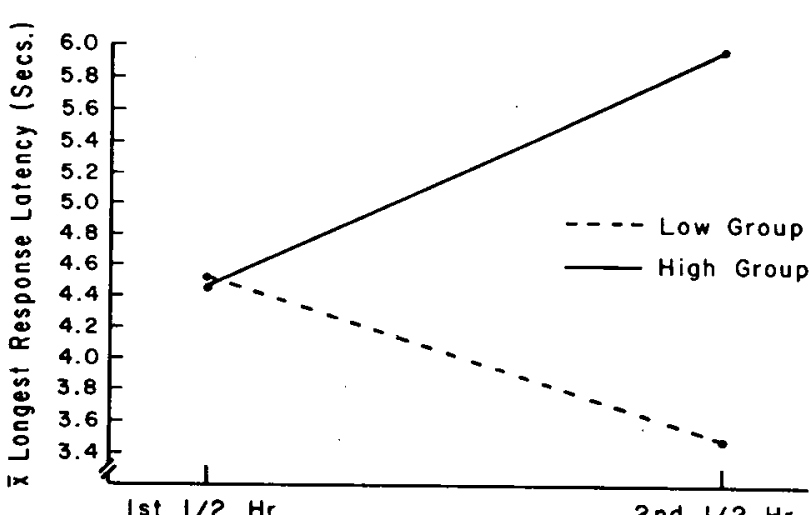

Ist $1 / 2 \mathrm{Hr}$.

2nd $1 / 2 \mathrm{Hr}$.

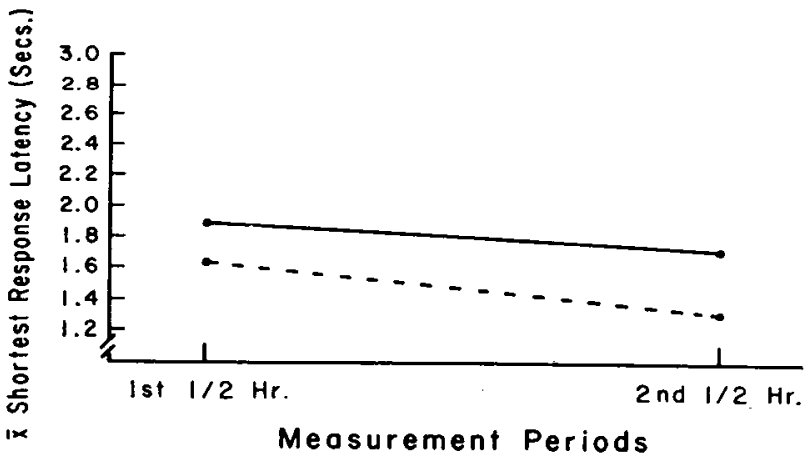

Figure 2. Mean shortest and longest latencies for the high and low boredom-monotony groups. between the two groups in mean latency to the critical stimuli, with the High Group having longer response times than the Low Group. For both mean latency and latency variability, there were significant $(p<.05)$ group-by-period interactions. The meaning of these significant effects is clarified in Figure 2. This figure plots the

TABLE 5. Mean Values Obtained for Each Performance

variable for the High and Low Boredom-Monotony Groups

\begin{tabular}{lllc}
\hline & & \multicolumn{2}{c}{ Measurement Period } \\
\cline { 4 - 4 } Variable & Group & 1 & 2 \\
\hline Latency to Critical & Low & 2.85 & 2.27 \\
Stimuli (sec) & High & 3.10 & 3.26 \\
SD of Latencies to & Low & 0.87 & 0.70 \\
Critical Stimuli (sec) & High & 0.82 & 1.31 \\
\hline
\end{tabular}

mean values of the single shortest and longest latencies for $S \mathrm{~s}$ in each group in the two halfhour periods. Analyses of variance conducted on these data revealed a significant $(p<.05)$ decline in shortest latencies during the first and second half hours for both groups, but no significant between-group or interaction effect. For the longest latencies, the only significant effect was the interaction effect $(p<.05)$. As Figure 2 reveals, the significant interaction effects for mean latency and latency variability shown in Table 5 can be attributed to an increase in the magnitude of "long response times" to the critical stimuli by the High Group and a decrease by the Low Group.

Rating scale data for both groups are shown in Table 6. Analyses of variance revealed significant differences $(p<.01)$ between the two measurement periods for all variables. While the High Group appeared to show greater changes from the beginning to the end of the task period than did the Low Group, the interaction effects were significant $(p<.05)$ for only two of the rating variables. These were attentiveness and strain, with the High Group showing a greater decrease in attentiveness and a greater increase in strain. There was also a significant difference between groups $(p<.05)$ on strain, but as Table 6 clearly reveals, this was simply a reflection of the significant interaction effect.

A final aspect of the data analysis was a comparison of the two groups with respect to scores 
YABLE 6. Mean Values obtained for Each Rating Scale Variable

for the High and Low Boredom-Monotony Groups

\begin{tabular}{llcc}
\hline & & \multicolumn{2}{c}{ Measurement Period } \\
\cline { 3 - 4 } Variable & Group & Prior to Task & End of Task \\
\hline Irritation $^{\mathbf{a}}$ & Low & 9.0 & 8.2 \\
& High & 9.0 & 6.4 \\
Attentiveness $^{\mathbf{a}}$ & Low & 3.6 & 4.4 \\
& High & 2.7 & 6.0 \\
Fatigue $^{\mathrm{b}}$ & Low & 4.4 & 5.7 \\
& High & 3.4 & 6.5 \\
Strain $^{\text {a }}$ & Low & 6.4 & 5.9 \\
& High & 6.4 & 3.5 \\
\hline
\end{tabular}

a Lower numerical values indicate higher levels of the variable.

b Higher numerical values indicate higher levels of the variable.

on the Extraversion scale of the Eysenck Personality Inventory and on the General Sensation Seeking and Boredom Susceptibility scales of the Zuckerman Sensation Seeking Scale. Scores on the Mean Extraversion, General Sensation Seeking, and Boredom Susceptibility scales were 12.4, 14.9, and 9.6 for the High Group and 12.6 12.6, and 7.6 for the Low Group. While the High Group had larger mean values than did the Low Group on both of the Zuckerman scales, $t$-tests revealed that none of the differences between groups on any of the scales was significant $(p>05)$.

\section{Discussion.}

With the possible exception of oral temperature, there was no evidence of any "postlunch dip" in physiological activity, performance, or subjective response. Thus, the suggestion of greater boredom and poorer performance among $S_{\mathrm{s}}$ in the early afternoon group of the pilot study was not supported by the present data.

For all three time-of-day groups, the physiological and subjective changes from the beginning (or first half hour) to the end (or second half hour) of the task period were generally in accord with the results of previous studies of such changes during performance of monotonous tasks. 256171825262728 The general pattern was one of a decline in conductance, oral temperature, blood pressure, heart rate, and attentiveness along with an increase in general body movement, boredom, irritation, fatigue, and strain Neither heart-rate variability nor task performance showed any change during the test session.
This latter finding is interesting, since a previous study of repetitive, monotonous performance revealed that increases in response variability (taken as an index of declining attention) were accompanied by increase in heart-rate variability. ${ }^{28}$ From the lack of change in heart-rate variability and task performance in the present study, it could be inferred that attention to the radar task showed little evidence of decline, even though the task was generally rated as somewhat boring and moderately monotonous. It should be noted, however, that although rated attentiveness declined from the beginning to the end of the task, the change was from a mean initial rating of "quite attentive" to a final rating of "attentive."

It is obvious that the pattern of physiological, performance, and subjective changes that occurred cannot be taken as uniquely representative of a monotony-boredom pattern; to do so would require comparing the pattern to that obtained on a task clearly rated as interesting to most $S$ s. Difficulties with this approach became evident during the initial pilot study. ${ }^{3}$ The alternative approach used in the present study was to compare patterns of $S$ s falling at the extremes of rated boredom and monotony. For the physiological and performance measures, significant differences between the groups were found for heart-rate variability and for mean and variability of latency to the critical task stimuli. The High Boredom-Monotony Group increased in these measures from the first to the second half of the session, while the Low Group decreased. The performance decrement shown by the High Group was found to be directly attributable to this group's increase in their longest response latencies. An increase in the frequency or duration of "long response times" in vigilance or repetitive tasks has been hypothesized to be a reflection of declining attention. ${ }^{611}$ Likewise, increased heart-rate variability has been linked in a variety of studies to indices of lowered or fluctuating attention.1923 2829 Of the two subjective measures significantly differentiating between the groups, one of these was attentiveness, with the High Group showing the greater decline. The High Group also experienced greater strain during the task period, possibly as a reaction to declining attention.

Theorists of boredom and monotony have tended to focus on "arousal" interpretations, 
with some conceiving of boredom and monotony as states of diminished arousal ${ }^{2122}$ and others, as states of heightened arousal. ${ }^{8}$ There was little evidence in the present study to support either view. Rather, the nature of the changes in those physiological, performance, and subjective variables that differed significantly between the extreme groups suggests that the principal pattern characterizing boredom and monotony was more closely related to attentional processes than to "arousal."

Protracted exposure to the task used, as was the case with Barmack's ${ }^{6}$ studies, might have resulted in significant relationships between reported boredom-monotony and some of the rather traditional physiological and subjective arousal indices employed here. However, the results of the present study imply that declining (or increasing) "arousal" is not a necessary cause of feelings of boredom and monotony.

There were no differences between the High and Low Boredom-Monotony Groups on either the Extraversion scale of the Eysenck Personality Inventory or the General Sensation Seeking and Boredom Susceptibility scales of the Zuckerman Sensation Seeking Scale. The lack of any relationship with extraversion was somewhat surprising, since several previous studies have shown this variable to be related to performance decrement on vigilance and repetitive tasks. ${ }^{4} 13151628$ Although the Zuckerman scales apparently have not been used in studies of complex vigilance, Zuckerman concedes that his scales, originally developed as possible predictors of response to sensory deprivation, have been poorest in this area of prediction. ${ }^{30}$ Boredom susceptibility is commonly felt to be an important factor in the inability to tolerate sensory deprivation.

It may be that the task employed in the present study was sufficiently novel and the length of exposure too short to allow extreme feelings of boredom and monotony to develop. Had Ss been exposed to the task over several adaptation periods, significant relationships with the Eysenck and Zuckerman scales might have been obtained. Future research using a computergenerated display will allow the use of extended adaptation periods and enable a more thorough investigation of possible relationships between personality variables and self-rated boredom and monotony.

\section{Conclusions.}

The results of this study clearly indicate a relationship between self-rated boredom-monotony and monitoring performance. Subjects who viewed the task as highly boring and monotonous showed a significant increase in their longest response times to the critical stimuli, while $S \mathrm{~s}$ who viewed the task as interesting and not monotonous showed a decrease in all measures of response time. The greater increase in heart-rate variability and decrease in rated attentiveness among the high boredom-monotony $S$ s suggests that these $S$ s were unable or unwilling to maintain a uniform level of task attention. The mean longest response time among the high boredom-monotony $S \mathrm{~s}$ was approximately $6 \mathrm{sec}-$ onds. While this value is not that impressive in itself, the task duration was relatively short, target density was not excessively high, and the $S$ was always aware that no stimulus could change until the next filmstrip was presented. It is quite likely that differences between high and low boredom-monotony $S$ s in response times to critical events would be more pronounced with a longer task duration, higher target densities, and fewer cues as to when critical changes might occur. Future research using a computergenerated radar display will incorporate some of these changes and enable a more comprehensive appraisal of the importance of individual differences in perceived boredom-monotony and monitoring performance. Further investigation of psychometric instruments that might predict boredom susceptibility is also planned. 


\section{REFERENCES}

1. Adams, J. A., H.. H. Stenson, and J. M. Humes : Monitoring of Complex Visual Displays-II. Effects f Visual Load and Response Complexity on Human Vigilance, HUMAN FACTORS, $3: 213-221,1961$.

2. Andreassi, J. L.: Skin-Conductance and ReactionTime in a Continuous Auditory Monitoring Task, AMERICAN JOURNAL OF PSYCHOLOGY, $79: 470$ 474,1966 .

3. Bailey, J. P.: Levels of Arousal: A Comparison of Conditions of Interest and Boredom. Unpublished master's thesis, Oklahoma State University, 1975.

4. Bakan, P.: Extraversion-Introversion and Improvement in an Auditory Vigilance Task, BRITISH

JOURNAL OF PSYCHOLOGY, 50:325-332, 1959 .

5. Baker, C. H.: Attention to Visual Displays Durin a Vigilance Task. II. Maintaining the Level of Vigilance, BRITISH JOURNAY OF PSYCHOLOGY, $50: 30-36,1959$.

6. Barmack, J. E. : Boredom and Other Factors in the

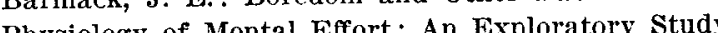
Physilogy of Mentaly ARCHIVES $218,1937$.

7. Barnes, L. B., and D. L. Dickson: Optimizing the Role of the Air Traffic Controller, JOURNAL O ATC, Jan.-Feb., 1973.

8. Berlyne, D. E.: Confict, Arousal, and Curiosity, New York, McGraw-Hill, 1960.

9. Berlyne, D. E. : Arousal and Reinforcement. In D. Levine (Ed.), Nebraska Symposium on Motivation, Vol. 15, Lincoln, Nebraska, University of Nebraska Press, 1967.

10. Blake, M. J. F.: Temperament and Time of Day In W. P. Colquhoun (Ed.), Biological Rhythms and Performance, New York, Academic Press, Inc., 1971.

11. Broadbent, D. E.: Decision and Stress, London, Academic Press, Inc., 1971

12. Cartwright, L. B.: The Effects of Broadband Nois on Certain Parameters of the Cardiovascular Syste in Normal Resting Adults. Unpublished doctor dissertation, University of Oklahoma, 1978

13. Claridge, G. S.: Personality and Arousal, London, Pergamon Press, 1967.

14. Colquhoun, W. P.: Circadian Variations in Mental Colquhoun, W. $\mathrm{P}$. Colquhoun (Ed.), Biological Rhythms and Performance, New York, Academic Press, Inc., 1971.

15. Corcoran, D. W. J.: Personality and the Inverted-U Relation, BRITISH JOURNAL OF PSYCHOLOGY, $56: 267-273,1965$.

16. Davis, D. R and G. R. J. Hockey: The Effects of Noise and Doubling the Signal Frequency on Indi- vidual Differences in Visual Vigilance Performance, BRITISH JOURNAL OF PSYCHOLOGY, $57: 381$ 389, 1966.

17. Davis, D. R., and A. Krkovic: Skin-Conductance, Alpha-Activity, and Vigilance, AMERICAN JOURNAL OF PSYCHOLOGY, $78: 304-306,1965$.

18. Eason, R. G., A. Beardshall, and S. Jaffee: Performance and Physion ance and Physiological Indicants of Aetivation in a SKILLS, $20: 3-13$, 1965 .

19. Ettema, J. H., and R. I. Zielhuis: Physiologica Parameters of Mental Load, ERGONOMICS, $14: 137$ 144, 1971.

20. Eysenck, H. J., and S. B. G. Eysenck: Eysenck Personality Inventory, San Diego, Education and Industrial Testing Service, 1968.

21. Fiske, D. W., and S. R. Maddi (Eds.): Functions of Varied Experience, Homewood, Ill., Dorsey, 1961.

22. Hebh, D. O.: Drives and the C.N.S. (Conceptual Nervous System), PSYCHOLOGICAL REVIEW, $62: 243-254,1955$.

23. Kagan, J. and B. L. Rosman: Cardiac and Respiratory Correlates of Attention and an Analytic AttiTUde, JOURNAL OF EXPERIMENTAL AND CHILD PSYCHOLOGY, 1:50-60, 1964

24. Lykken, D. T., and P. H. Venables: Direct Measure ment of Skin Conductance: A Proposal for Standardization, PSYCHO-PHYSTOLOGY, $8: 656-672,1971$.

25. Stern, R. M. : Performance and Physiological Arousal During Two Vigilance Tasks Varying in Signal Presentation Rate, PERCEPTUAL AND MOTOR SKILIS, 23 :691-700, 1966.

26. Surwillo, W. W.: The Relation of Autonomic Activ ity to Age Differences in Vigilance, JOURNAL OF GERONTOLOGY, $21: 257-260,1966$.

27. Thackrav, R. I., K. N. Jones, and R. M. Touchstone: Self-Estimates of Distractibility as Related to Performance Decrement on a Task Requiring Sustained Attention, ERGONOMICS, 16:141-152, 1973.

28. Thackray, R. I., K. N. Jones, and R. M. Touchstone Personality and Physiological Correlates of Per formance Decrement on a Monotonous Task Requiring Sustained Attention, BRITISH JOURNAL OF PSYCHOLOGY, $65: 351-358,1974$.

29. Welford, $Y$. T.: Heart-Rate Variability During Continuous Performance. Paper presented at the meeting of the American Association for the Advancement of Science, Dallas, December 1968.

30. Zuckerman, M.: Manual and Research Report for the Sensation seeking scale (SSS), Newark, N.J. University of Delaware, 1972 
